\title{
Benchmarking and Potential of Heat Pumps for Flue Gas Condensation
}

\author{
W. Wedel ${ }^{1,2} *$ A. Vandersickel ${ }^{1}$, H. Spliethoff ${ }^{1,3}$ \\ ${ }^{1}$ Technical University of Munich, Institute for Energy Systems, Garching, Germany \\ ${ }^{2}$ Technical University of Munich, Munich School of Engineering, Garching, Germany \\ ${ }^{3}$ Bavarian Centre for Applied Energy Research, Garching, Germany \\ E-mail: ${ }^{1}$ wolf.wedel@tum.de
}

Received 20 December 2018, Revised 21 August 2019, Accepted 02 September 2019

\begin{abstract}
The use of environmental or waste heat with heat pumps, open absorption cycles or sorption heat pumps is an option for low carbon or high efficiency heat supply for industrial use. For one of the mentioned technologies to experience wide spread application it must offer economic advantages compared to other technologies. The evaluation of the economic viability is strongly dependent on boundary conditions, especially the cost of gas and electricity.

The scope of this work is to introduce a new methodology, the specific annuity difference method. The developed methodology can improve on the one hand the comparison of different heat recovery technologies based solely on their cost and coefficient of performance (COP) and, on the other hand, allows for companies and researchers to identify if investment cost or efficiency improvement is more important to grant economic viability given a specific gas and electricity price. Additionally the maximum amount of heat that can potentially be recovered from the flue gas of gas boilers and gas turbines using an active condensing technology is compared for different COPs, temperature differences between cooled gas and heated water and different return temperatures, in order to quantify potential efficiency improvements for both technologies.
\end{abstract}

Keywords: Condensing technology; energy efficiency; heat pump; waste heat.

\section{Introduction}

Due to the many parameters influencing energetic and economic feasibility of condensing technologies, it is a complex task to adequately compare different technologies, which allow for flue gas condensation. [1] analyzes flue gas condensation in industrial applications, heat pumps are mentioned as feasible but costly option for recovery of latent heat at higher return temperatures and investment decision of conventional condensing technology is said to be casedependent. A net present value analysis is used to evaluate between carbon and stainless steel condensers. The use of heat recovery technologies is many times evaluated through techno-economic case studies, examples are e.g. [2-5]. If case studies take into account variable parameters such as carbon emission cost, electricity or fuel cost, it is done to find an economically feasible application or consider a certain risk, but not to account for changing boundary conditions in all dimensions, as this would require a variation of all the costs and values relating to the case. Technology evaluation and comparison limited to specific applications are certainly of interest as detailed questions of application are investigated, yet their significance and validity, especially regarding economic decisions, might be limited to the specific case and very similar boundary conditions. In a world of ever changing economic and political environment, a wrong assumption concerning gas and electricity price development or failure to anticipate political decisions, such as carbon emission trading and taxation, may diminish the relevance of research work, even before publication.

To address this topic a methodology has been developed, which allows comparing different technologies for flue gas condensation and heat pump usage in general. The approach itself can be altered and used for the evaluation of different technologies. It is intended for site operator and owner, which seek to decide which technology to apply in their specific system, as well as for technology developers and researchers to make well-founded decisions regarding technology development. All the values and ranges for which variations are made are intended to represent a broad range of relevant data sets, allowing the majority of cases to be covered without recalculation effort.

\section{Methodology}

The topic of the application of flue gas condensation and heat pump usage in general must be divided in two parts, which are not completely, yet with regard to important decision making criteria, independent. These two aspects are firstly the potential for flue gas condensation or heat reservoir usage, and secondly, the economic viability of a solution.

\subsection{Flue gas potential}

The potential of flue gas condensation for natural gas application depends mostly on the air ratio of combustion, which is technology specific, and temperature levels of flue gas and process water. In this work flue gas potential of natural gas technologies in general is considered. All calculations are performed under the assumption of existing technology, which may be upgraded with an active flue gas condensation system. Since the temperature level of heat during natural gas combustion is high, it is assumed that flue gas condensation is used to preheat the return flow before 
using the existing heat exchanger to heat the water up to process temperature.

For the calculations a model system, represented in Figure 1, is used. The fuel input is one MW higher heating value (HHV) of pure Methane, no losses other than exhaust losses are considered. Fuel and air are supplied at ISO 2533 conditions at 1.01325 bar and $15{ }^{\circ} \mathrm{C}$, the composition is given in Table 1.

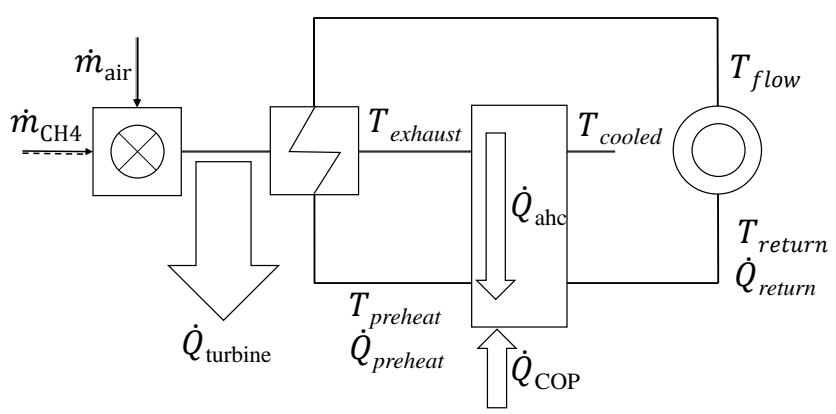

Figure 1. Model system for flue gas potential evaluation.

Table 1. Composition of combustion air.

\begin{tabular}{l|llll} 
compound & $\mathrm{N}_{2}$ & $\mathrm{O}_{2}$ & $\mathrm{Ar}$ & $\mathrm{CO}_{2}$ \\
mass fraction, $\%$ & 75.53 & 23.14 & 1.29 & 0.04 \\
\hline
\end{tabular}

\subsection{Flue Gas Potential}

Methane and air are mixed and burned in a combustion chamber. Air is supplied at 1.15 times and four times the stoichiometric ratio. These are typical air ratios of two of the prevalent natural gas technologies, boiler and gas turbine. To account for energy extracted from the exhaust gases in order to generate electricity in the case of the gas turbine, a heat loss of $350 \mathrm{~kW}$ after the combustion chamber is introduced in all cases with an air ratio $\lambda$ of four. In the industry, there are many different heat exchanger design configurations and temperature differences regarding the heat consumer. To estimate the actual design of (non condensing) heat exchangers, the approach temperature between flue gas exiting and process water entering the heat exchanger $\Delta T_{\text {hex }}$ is set to $20 \mathrm{~K}$. A closer approach leads to higher equipment cost and pressure drop, while improving possible heat recovery from the flue gas. A greater approach temperature has the opposite effect.

$\Delta T_{\text {hex }}=T_{\text {exhaust }}-T_{\text {preheat }}$

For the temperature difference between return temperature and flow temperature, $\Delta T_{\text {cons }}$, two cases, $20 \mathrm{~K}$ and $40 \mathrm{~K}$, are considered, as these are typical design temperature differences of heating networks. Comparing results from these two cases enables a quantification of the heating networks design temperature difference influence on heat recovery potential.

$\Delta T_{\text {cons }}=T_{\text {flow }}-T_{\text {return }}$

Active flue gas condensation is represented as a heat loss $\dot{Q}_{a h c}$ in the flue gas after the heat exchanger and as heat added to the water stream before entering the heat exchanger. The use of an active condensing system implies that additional heat enters the process fluid due to work performed in the active component (e.g. heat pump). This heat $\dot{Q}_{C O P}$ is calculated as given in (3).
$\dot{Q}_{C O P}=\frac{\dot{Q}_{a h c}}{C O P-1}$

The calculation of flue gas potential is performed in EBSILON®Professional (EBSILON) and consists of two steps and an iteration as represented by the flow chart in Figure 2.

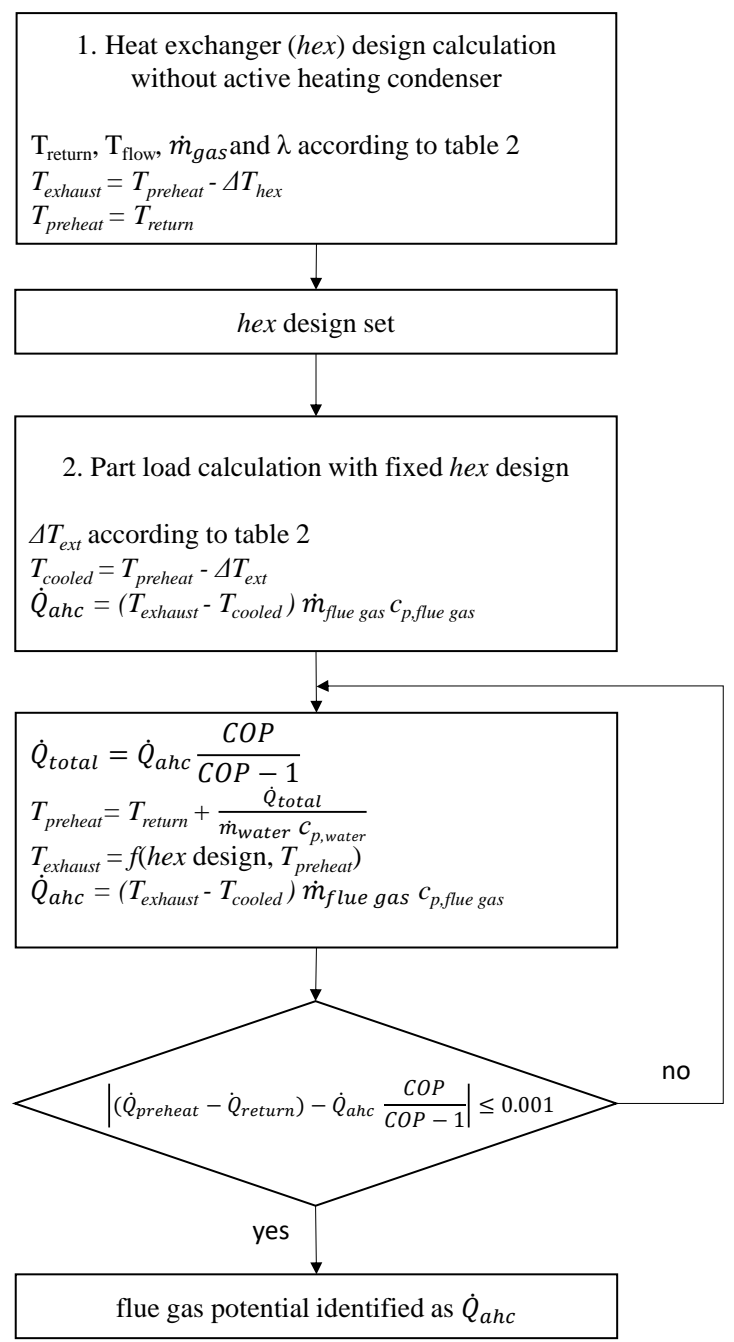

Figure 2. Flow chart of flue gas potential calculation

First a design calculation of the heat exchanger is performed. The heat exchanger area is adjusted while flue gas exit and heat consumer return temperature are set to the desired values and water mass flow is adjusted in a way, such that the desired flow temperature, $20 \mathrm{~K}$ or $40 \mathrm{~K}$ above the return temperature, is reached.

In a second step, a part load calculation is performed to simulate an existing system being upgraded via active flue gas condenser technology. To represent the different possible configurations different external temperature differences $\Delta T_{\text {ext }}$ between preheated water and cooled flue gas, ranging from $10 \mathrm{~K}$ to $80 \mathrm{~K}$, are assumed. The external temperature difference is defined as

$\Delta T_{\text {ext }}=T_{\text {preheat }}-T_{\text {cooled }}$.

The heat flow $\dot{Q}_{\text {total }}$ resulting from heat transfer from flue gas during cooling to water during preheating adjusted by a factor to account for energy added due to the power supplied to the active condensing technology, is added to the water previous to it entering the heat exchanger. 
$\dot{Q}_{t o t a l}=\dot{Q}_{a h c} \frac{C O P}{C O P-1}=\dot{Q}_{a h c}+\dot{Q}_{C O P}$

This affects the water temperature after preheating, resulting in a higher $T_{\text {preheat }}$ and, according to (1) to a lower $T_{\text {exhaust }}$. Therefore, $\dot{Q}_{a h c}$ changes and (5) is used to calculate a new $\dot{Q}_{\text {total }}$ resulting in a new $T_{\text {preheat }}$. This calculation is repeated until the difference between the corrected heat taken from the flue gas $\dot{Q}_{\text {total }}$ and the heat flow difference between return flow and preheated flow are small according to (6).

$\left|\left(\dot{Q}_{\text {preheat }}-\dot{Q}_{\text {return }}\right)-\dot{Q}_{\text {ahc }} \frac{C O P}{C O P-1}\right| \leq 0.001$

To investigate part load performance, EBSILON specific part load calculation of heat transfer for once-through heat exchanger is used. Water mass flow in part load is adjusted to meet the specific predefined temperature difference between return and flow temperature. In the calculation rising pressure losses due to rising mass flow are not taken into account, but must be kept in mind as they represent an important limitation of existing systems. For the process water, a constant pressure of 15 bar is assumed. Assumptions and ranges of the parameter variations made for the evaluation of heat recovery potential and simulation are listed in Table 2.

Table 2. Assumptions and variation ranges for flue gas potential evaluation.

\begin{tabular}{|c|c|c|c|}
\hline Variable & Name & Range & Unit \\
\hline return temperature & $\mathrm{T}_{\text {ret }}$ & $60-140$ & ${ }^{\circ} \mathrm{C}$ \\
\hline $\begin{array}{l}\text { temperature difference over } \\
\text { consumer }\end{array}$ & $\Delta \mathrm{T}_{\text {cons }}$ & $20 ; 40$ & $\mathrm{~K}$ \\
\hline $\begin{array}{l}\text { external temperature difference of } \\
\text { active condensing technology }\end{array}$ & $\Delta \mathrm{T}_{\mathrm{ext}}$ & $10-80$ & $\mathrm{~K}$ \\
\hline coefficient of performance (COP) & COP & $1.5-99$ & - \\
\hline $\begin{array}{l}\text { Temperature difference, gas outlet, } \\
\text { water inlet of heat exchanger }\end{array}$ & $\Delta \mathrm{T}_{\text {hex }}$ & 20 & $\mathrm{~K}$ \\
\hline Air ratio & $\lambda$ & $1.15 ; 4$ & - \\
\hline
\end{tabular}

\subsection{Economic Viability}

In the discussion regarding active flue gas condensation and ambient heat use, it is important to note, that an economically viable application does not primarily depend on potential and temperature levels, but on cost and performance of the heat pump technology in comparison to other solutions. Cost includes four different parameters. Investment in the heat pump technology and the cost of an alternative technology (typically a gas boiler), maintenance spending and the fuel prices for both (gas for the alternative gas boiler) as well as the cost of the energy used to power the heat pump system (usually gas or electricity). All those parameters are influenced by inflation, interest rates and changes in the energy market. On the operating and thermodynamic side, full load hours and COP of the system are the most important aspects. Of course, temperature differences, resulting potentials and technology choices influence the cost and therefore the economic viability. Yet the most important aspects can be considered, regarding only economic parameters.

To consider as many of the parameters at once a novel approach based on the specific annuity difference is chosen. The annuity [6] combines the variables investment cost, interest rate, depreciation period and inflation with maintenance spending to a single value which is usually given in $€ \mathrm{a}^{-1}$. The annuity difference $\Delta a$ is the difference between the annuities of the active condensing system $a_{a \mathrm{hc}}$ and an alternative benchmark system $a_{\text {bench }}$ (e.g. a gas heater). If the installation of an alternative system is compulsory for e.g. back up heating or peak loads, the second part of equation (7) is zero and the annuity difference equals the active condensing technologies annuity.

$\Delta a=a_{a h c}-a_{\text {bench }}$

Dividing the annuity difference by the expected yearly full load hours $f l h$ results in the specific annuity difference $\Delta a_{\text {spec }}$ in units of $€ \mathrm{MW}^{-1} \mathrm{~h}^{-1}$.

$\Delta a_{\text {spec }}=\frac{\Delta a}{f l h}$

Since the assumption of fixed energy prices does not represent the actual market situation and does not represent the risk of losing an investment due to changes in cost or politics, a variation of energy costs is performed. The assumed electricity costs are listed in Table 3, based on the range of European industry prices for electricity [7]. In the case of gas not only the price on the international markets and additional spending due to energy taxes are important. Because of European $\mathrm{CO}_{2}$-emission trading and taxation in individual countries the cost of carbon dioxide emissions can add substantially to the total cost of gas consumption. Whereas the energy and emission taxes on gas are more or less stable in most countries even though they depend on politics, emission trading can potentially lead to varying costs within very short periods.

To raise awareness for this issue and allow results to be applicable in countries with different energy and carbon dioxide emission taxation, a combined gas price $c_{c g a s}$ as defined in (9) has been defined. The cgas price is calculated as the sum of the gas price $c_{g a s}$ including energy or other taxes with the cost of emitting carbon dioxide $c_{\mathrm{CO} 2}$ multiplied by the emission factor $\varepsilon$. This factor is here set to 0.181 tons $\mathrm{MWh}_{\mathrm{HHV}^{-1}}$ since in this example pure methane is considered. This is close to the emissions caused by burning of natural gas with high methane content such as e.g. Russian H-gas.

$c_{c g a s}=c_{g a s}+\varepsilon c_{C O 2}$

Energy to power the benchmark technology $c_{\text {energy,bench }}$ is assumed to be supplied by gas and is calculated according to (10) with an assumed HHV-efficiency $\eta$ of 0.8 .

$c_{\text {energy,bench }}=\frac{c_{\text {cgas }}}{\eta}$

To evaluate the active condensing technology it is necessary to take into account $\mathrm{COP}$ and electricity price per MWh $c_{\text {elec, }}$ such that $c_{\text {energy,ahc }}$ is the cost of electricity to produce one MWh of heat.

$c_{\text {energy, ahc }}=\frac{c_{\text {elec }}}{C O P}$

If the system is powered by gas, the formulation

$c_{\text {energy,ahc }}=\frac{c_{\text {cgas }}}{C O P}$,

results.

To assess the economic performance of different technologies independent of technological aspects (apart 
from the COP) a formulation (13) is developed. It represents the cost difference $\Delta c$ per hour and $\mathrm{MW}_{\text {installed capacity }}$ between the considered technology and the benchmark and consists of the specific annuity difference and the difference in energy cost for using both technologies.

$\Delta c=\Delta a_{\text {spec }}+c_{\text {energy,ahc }}-c_{\text {energy,bench }}$

Setting the difference $\Delta c$ to zero and reformulating to give an expression for $c_{\text {cgas }}$, (14) for an active condensing technology powered by electricity and (15) for one powered by gas is achieved.

$c_{\text {cgas }}=\eta\left(\Delta a_{\text {spec }}+\frac{c_{\text {elec }}}{\text { COP }}\right)$

$c_{\text {cgas }}=\frac{\Delta a_{\text {spec }}}{\eta^{-1}-\mathrm{COP}^{-1}}$

If solved for a variety of electricity prices, the result is the cgas price, at which cost competitiveness between the active condensing technology and the benchmark, depending on COP and specific annuity difference, is reached. The ranges in which the parameters for the economic evaluation are varied and their assumed values are summarized in Table 3.

Table 3. Assumptions and ranges for the evaluation of economic viability.

\begin{tabular}{llll}
\hline Variable & Name & Range & Unit \\
\hline Specific annuity difference & $\Delta \mathrm{a}_{\text {spec }}$ & $0-60$ & $€ \mathrm{MW}^{-1} \mathrm{~h}^{-1}$ \\
Cost of electricity & $\mathrm{c}_{\text {elec }}$ & $40 ; 80 ; 120 ; 160$ & $€ \mathrm{MWh}^{-1}$ \\
Natural gas cost & $\mathrm{c}_{\text {cgas }}$ & $30-60$ & $€ \mathrm{MWh}^{-1}$ \\
$\mathrm{CO}_{2}$ tax/trading cost & $\mathrm{c}_{\text {carbon }}$ & $0-125$ & $€ \operatorname{ton}^{-1}$ \\
Coefficient of performance & $\mathrm{COP}$ & $1-7$ & - \\
\hline
\end{tabular}

\section{Results and Discussion}

Results from potential analysis and economic evaluation are discussed separately, as one does not directly influence the other.

\subsection{Flue gas potential}

Heat recovery potential from the flue gas depending on return temperature and external temperature lift of the active condensing system for a gas heater $(\lambda=1.15)$ and a temperature difference between flow and return temperature of $20 \mathrm{~K}$ has been calculated. In order to quantify the influence of COP and resulting heat $\dot{Q}_{C O P}$ on the heat recovery potential, four cases are considered. A COP of 1.5 and two, as extreme cases in which the amount of $\dot{Q}_{C O P}$ is relatively high, seven as an optimistic upper boundary and 99 in the case of which the influence of $\dot{Q}_{C O P}$ is negligible, are considered. The results are visualized in Figure 3. A COP of 99 is not achievable for the here assumed temperatures and temperature differences. As the theoretical maximum for the COP is the inverse of the Carnot efficiency, also a part of the results for a COP of seven will not be reached with the proposed temperature differences of up to $80 \mathrm{~K}$. The theoretical limit is marked in graph (c) with the dotted line, the area above which cannot be reached. In real-life applications flue gas would not be cooled to the point assumed here for low return temperatures and high external temperature differences, due to chimney draft and availability of environmental heat at higher temperatures.

The COP's influence on general flue gas potential is little for all four cases. Maximum potential is about
$160 \mathrm{~kW}_{\text {heat }} \mathrm{MW}_{\mathrm{CH} 4, \mathrm{HHV}^{-1}}$ at minimal $T_{\text {ret }}$ and maximal $\Delta T_{\text {ext }}$. Minimal potential is reached at high $T_{\text {ret }}$ and low $\Delta T_{\text {ext }}$ and is about $12.7 \mathrm{~kW}_{\text {heat }} \mathrm{MW}_{\mathrm{CH} 4, \mathrm{HHV}^{-1}}$ for the four considered COP cases. The difference in flue gas potential is based on the greater amount of preheating at lower COP values, as those represent higher amounts of heat added during the preheating due to $\dot{Q}_{C O P}$.
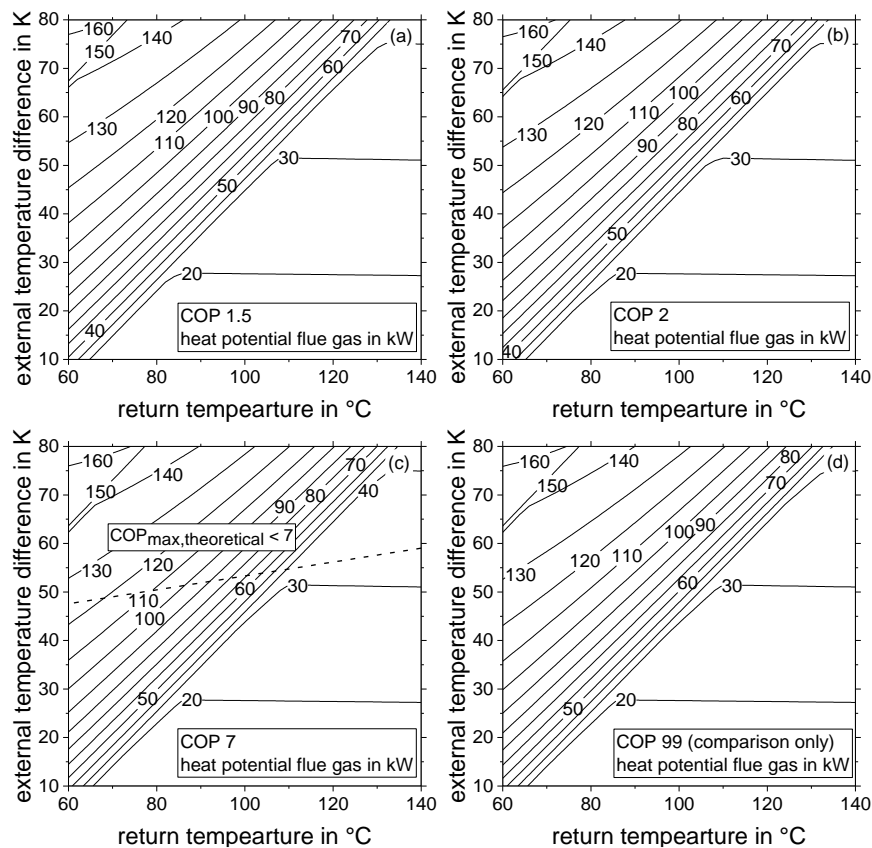

Figure 3. Flue gas potential in $k W, 1 M W_{H H V}$ gas input, $\lambda=1.15$. COP of 99 not achievable due to thermodynamics, COP of seven only partly possible.

To visualize the influence of the COP, Figure 4 has been derived. It displays the difference in flue gas potential between the cases of COP 1.5 and 99 . Flue gas potential is higher the higher the COP of the system. The differences at low return temperatures and high external temperature lifts as well as for high return temperatures and low external temperature lifts are smaller than $1 \%$ of total potential in the case of $\mathrm{COP}=99$. The greatest differences are reached in an area from $T_{r e t}=60{ }^{\circ} \mathrm{C}$ and $\Delta T_{e x t}=10 \mathrm{~K}$ to $T_{r e t}=130{ }^{\circ} \mathrm{C}$ and $\Delta T_{\text {ext }}=80 \mathrm{~K}$.

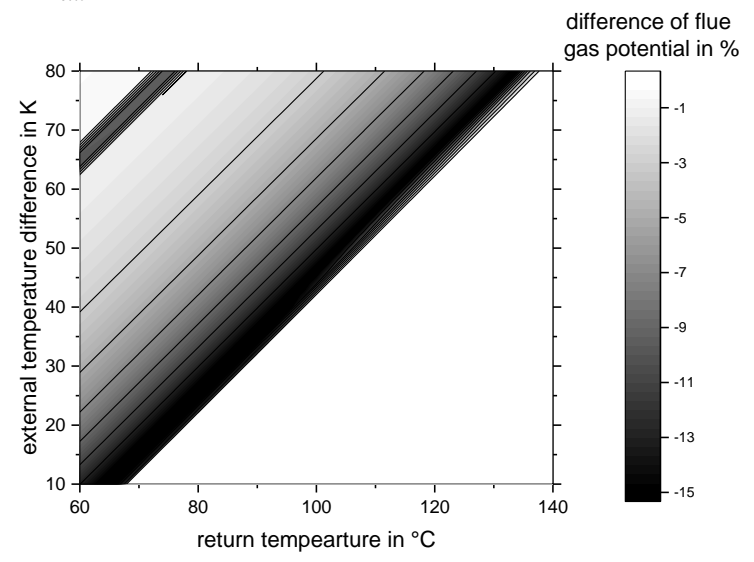

Figure 4. Difference in flue gas potential between a COP of 1.5 and 99 for $\Delta$ Tcons $=20 K, \lambda=1.15$.

The gradient is greater in the direction from the maximal differences to higher temperatures and lower temperature differences, as the potential differences below the diagonal fall rapidly to nearly zero. Above the diagonal a smaller 
gradient is reached, differences of $1 \%$ are only reached for $\Delta T_{\text {ext }}>63 \mathrm{~K}$ and $T_{\text {ret }}<77^{\circ} \mathrm{C}$. The inverse occurs for the second area of greater differences, starting at $T_{r e t}=60^{\circ} \mathrm{C}$ and $\Delta T_{\text {ext }}=65 \mathrm{~K}$ to $T_{r e t}=75^{\circ} \mathrm{C}$ and $\Delta T_{e x t}=80 \mathrm{~K}$. The differences in gradients and the position of the greatest differences in potential are due to the beginning of the phase change of water in the flue gas.

The greater differences at lower flue gas temperatures result from the heat of solidification and those at higher flue gas temperatures from the heat of condensation. With lower COP, the greater amount of added heat leads to a slightly lower cooling of the flue gas. Therefore, in the area of greatest differences, a phase change of the water in the flue gas can no longer be achieved, as the lowest flue gas temperature depends on the temperature of the preheated return flow. Results for the comparison of difference in potentially recoverable heat between the cases with a COP of two and seven are similar, with maximum differences of $9.4 \%$. These results show that in the case of flue gas condensation the influence of the COP on recoverable heat cannot be neglected if only little flue gas condensation is achieved at the design point. If no condensation or high condensation is achieved the influence of the COP on flue gas potential is small. As the results for $\Delta T_{\text {cons }}=40 \mathrm{~K}$ are similar they are not displayed.

In Figure 5, calculated flue gas potential for boiler (on the left) and gas turbine (on the right) with a COP of two are displayed. The results in the first row (e and f) are achieved with $\Delta T_{\text {cons }}=20 \mathrm{~K}$ and in the second row ( $\mathrm{g}$ and $\mathrm{h}$ ) with $\Delta T_{\text {cons }}=40 \mathrm{~K}$. The results for the other COPs are not shown due to little variation in overall potential as demonstrated before.
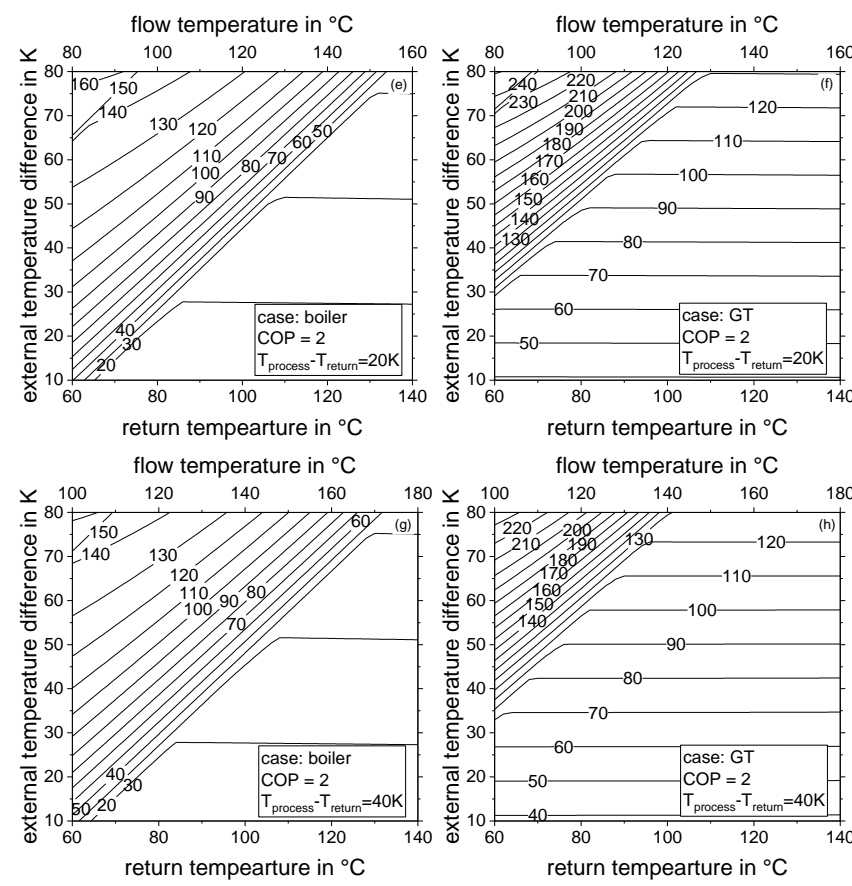

Figure 5. Flue gas potential in $\mathrm{kW}$ for a COP of $2, \lambda=1.15$, $\lambda=4$ and $\Delta$ Tcons $=20 \mathrm{~K}, \Delta$ Tcons $=40 \mathrm{~K}$.

Considering the case of $\lambda=1.15$ the potential for $\Delta T_{\text {cons }}=20 \mathrm{~K}$ and $40 \mathrm{~K}$ varies only slightly and is a little lower for the latter. This is due to elevated temperatures resulting from a lower water mass flow because of the higher temperature difference at nearly the same energy uptake. The same is valid for the cases with $\lambda=4$. As the flow temperature in the case of $\Delta T_{\text {cons }}=40 \mathrm{~K}$ is significantly higher than at $\Delta T_{\text {cons }}=20 \mathrm{~K}$, this results in the possibility to apply active flue gas condensation even if flow temperatures are high, as with this configuration the flue gas potential depends almost completely on return temperature and external temperature lift. Preheating the return flow with an active condensing system opens up greater flue gas potential than completely heating up a bypass stream (at equal $\Delta T_{\text {ext }}$ ) and allows for better utilisation of the exergy of natural gas, since heat is transferred at lower temperature differences.

The comparison of left and right side of Figure 5 allows the evaluation of the influence of a greater air to fuel ratio on flue gas potential.

Firstly the condensation, visible through the change of gradients of flue gas potential in the figure, shifts to higher external temperature differences and lower return temperatures at $\lambda=4$. This is due to a lower water content of the flue gas, shifting the dew point to lower temperatures. Secondly, the available heat is up to three times greater for gas turbines (GT). To compare the differences between cases (e) and (f) the ratio between flue gas potential in the case of $\lambda=4$ and in the case of $\lambda=1.15$ is plotted in Figure 6 .

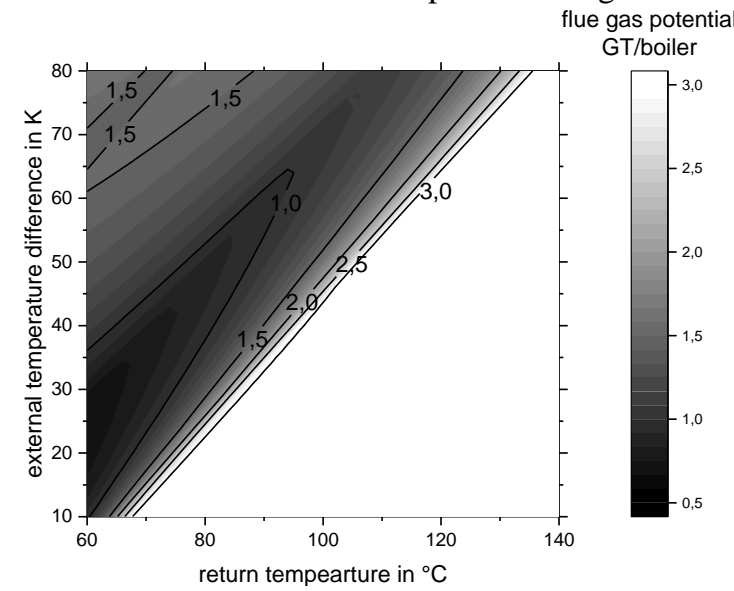

Figure 6. Ratio of flue gas potential between $G T(\lambda=4)$ and boiler $(\lambda=1.15)$ for $C O P=2, \Delta T$ cons $=20 \mathrm{~K}$.

The boiler has a higher potential than the GT in the area of a potential ratio smaller than one. As flue gas condensation for the lower air to fuel ratio starts at higher temperatures and lower temperature differences, the difference between the flue gas potential becomes smaller as flue gas condensation starts in the case of the boiler and does not take place for higher air to fuel ratios. Therefore, at small temperature differences and low return temperatures the amount of available heat is higher in case of the boiler than in case of the gas turbine. This is due to latent heat recovered in the boiler outweighing the sensible heat recovered in the case of the GT. As soon as flue gas condensation starts in the GT's flue gas, the greater amount of sensible heat combined with the now available latent heat lead to a higher gradient of availability of heat in the case of higher air to fuel ratios. This leads to the GT's flue gas potential at maximal flue gas condensation being about 1.6 times higher in both cases.

\subsection{Economic viability}

Calculation of the combined gas price results in Figure 7, showing the linear dependency from (9). Relevant areas are marked in the graph. These are based on the carbon price resulting from taxes and emission trading [8], [9] and inflation adjusted historic natural gas price between $5.53 \$ \mathrm{MWh}^{-1}$ in March 2016 and $62.78 \$ \mathrm{MWh}^{-1}$ in September 2015 [10] with no taxation and planned taxation 
of $31.8 € \mathrm{MWh}^{-1}$ in Germany [11] as an example. It must be kept in mind, that political changes and market mechanisms in emission trading and the gas market can lead to quick changes of the situation in a specific country.

The results from (14) for the values and ranges specified in Table 3 are plotted in Figure 8. If changing operating points are considered, COP must be substituted with seasonal energy efficiency Ratio (SEER) to calculate economic effects on the overall performance.

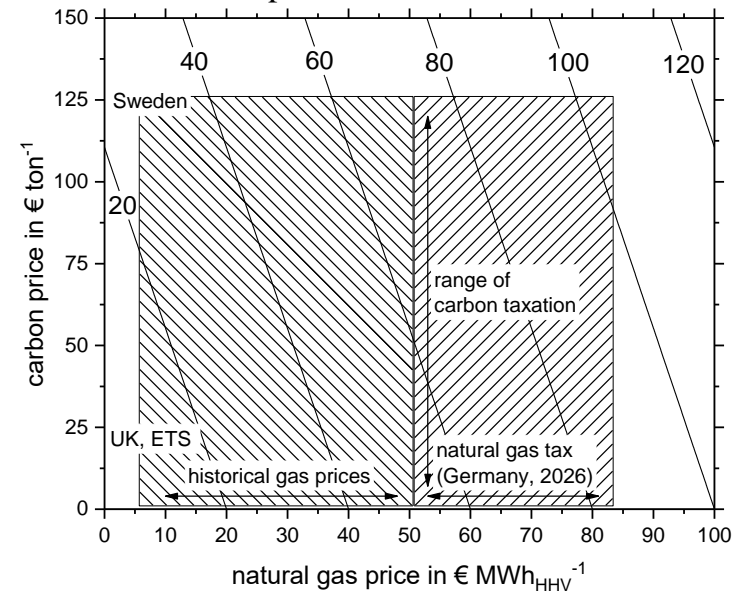

Figure 7. Linear dependency between cgas price in $€$ $M W h_{H H V^{-1}}$ and natural gas price, carbon price, historical, current and future taxes and prices indicated.
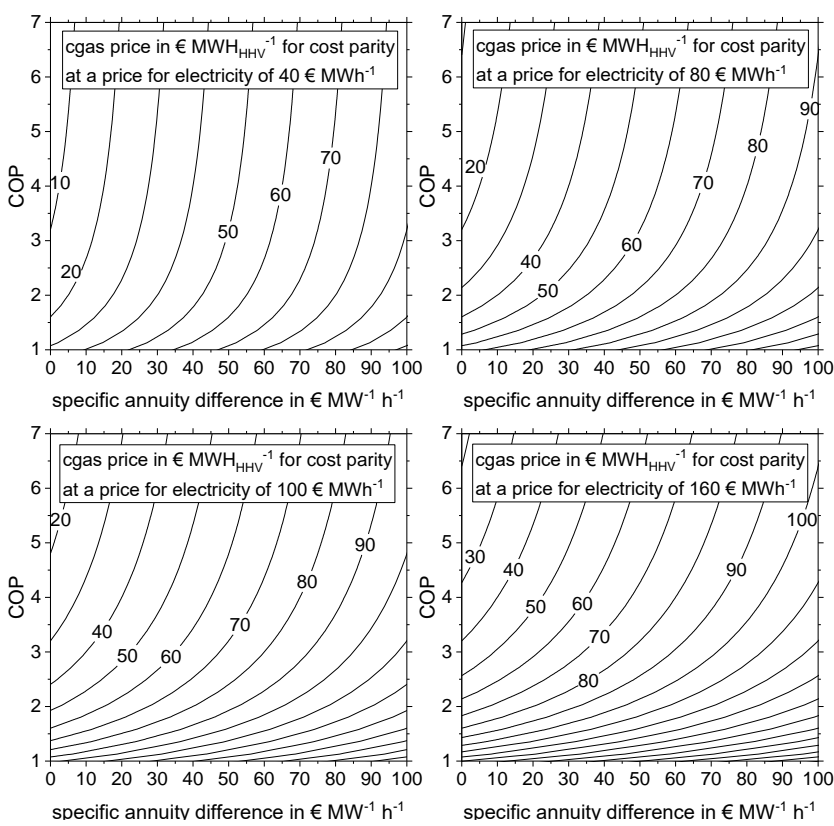

Figure 8. Combined gas price results in $€ M W h_{H H V}^{-1}$ for parity between heat production via boiler and active heat recovery system for different electricity prices (40, 80, 120 and $160 € \mathrm{MWh}-1)$ at boiler efficiency (HHV) 0.8 .

Limiting the evaluation to the relevant $c_{\text {cgas, limit,elec }}$ derived from Figure 6, the relevant range for the specific annuity difference is chosen to be from zero, e.g. funded by research projects, to $100 € \mathrm{MW}^{-1} \mathrm{~h}^{-1}$, at which a $\mathrm{c}_{\mathrm{cgas}}$ of more than $80 €$ $\mathrm{MWh}_{\mathrm{HHV}^{-1}}$ would be necessary to achieve cost parity. The results show the asymptotic behaviour of the cost parity contours. The influence of the COP is greater at low COPs and declines for higher COPs. This characteristic is stronger for lower electricity costs and lower specific annuity differences. For $\Delta a_{\text {spec }}$ of zero at the lowest considered electricity price of $40 € \mathrm{MWh}^{-1}$ a heat pump/heat recovery system with a COP of two reaches cost parity when the cgas price is as low as $16 € \mathrm{MWh}_{\mathrm{HHV}}{ }^{-1}$ while at an electricity price of $160 € \mathrm{MWh}^{-1}$ a combined gas price of $64 € \mathrm{MWh}_{\mathrm{HHV}}{ }^{-1}$ would be necessary.

Someone searching to apply a heat pump system can use this representation and easily identify the necessary COP and the maximum cost of the system for it to be economically viable, depending solely on the price the company pays for gas and electricity. In addition, this representation allows assessing the value of a COP improvement of a heat pump system, independent from operating conditions.

In markets with higher electricity prices, the COP is more important for the economic application of the system than in markets with lower electricity prices. This influence is stronger for lower COPs than for higher ones. On the contrary, the influence of the specific annuity difference is quite independent of the other parameters. The different trends are summarized in Table 4 . For a company selling heat pump systems, a lower $c_{c g a s}$ to achieve cost parity means the system can be applied economically in more applications as the threshold price of gas is lowered.

\section{Table 4. Influences of COP and electricity price on} economic viability in different market and technology situations.

\begin{tabular}{l|llllll}
\hline $\begin{array}{l}\text { Influence } \\
\text { of }\end{array}$ & at low & at high & at low & at high & at low & at high \\
\hline COP & COP & COP & $\mathrm{c}_{\text {elec }}$ & $\mathrm{c}_{\text {elec }}$ & $\Delta \mathrm{a}_{\text {spec }}$ & $\Delta \mathrm{a}_{\text {spec }}$ \\
\hline $\mathrm{c}_{\text {elec }}$ & $\uparrow$ & $\downarrow$ & $\downarrow$ & $\uparrow$ & $\rightarrow$ & $\rightarrow$ \\
$\Delta \mathrm{a}_{\text {spec }}$ & $\rightarrow$ & $\downarrow$ & $\rightarrow$ & $\rightarrow$ & $\uparrow$ & $\uparrow$ \\
\hline
\end{tabular}

The influence of $\Delta a_{\text {spec }}$ and COP on the $c_{c g a s}$ for cost parity concerning a gas powered heat pump system is depicted in Figure 9.

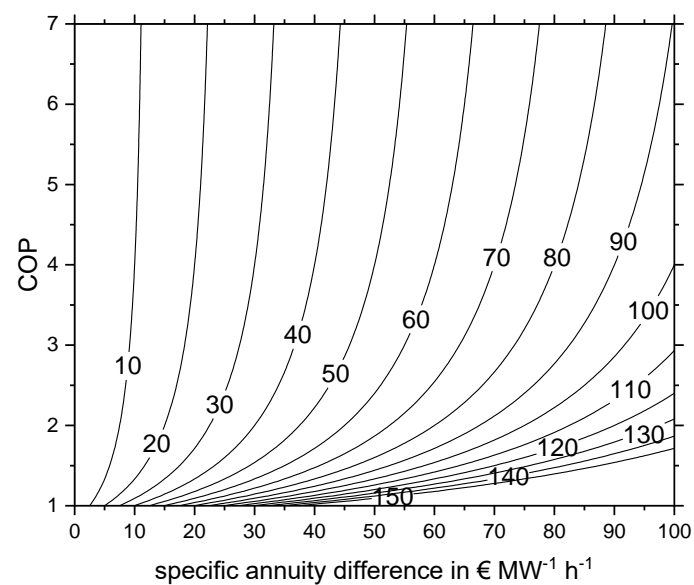

Figure 9. Combined gas price results in $€ M W h_{H H V^{-1}}$ for price parity between heat production via boiler and active heat recovery system powered with gas, at a boiler efficiency (HHV) of 0.8 .

The contours for parity gas cost with a gas boiler start at a COP of 0.8 (not displayed) at $\Delta a_{\text {spec }}$ of zero. This results from the choice of a benchmark efficiency of 0.8 . The contours spread out and become nearly vertical for high COPs. For higher $\Delta a_{\text {spec }}$, the COP influences the allowed $c_{c g a s}$ stronger than in the case of lower specific annuity differences. At low COPs the influence of $\Delta a_{\text {spec }}$ and COP are greater than at high COPs. The results show that for gas driven systems cost reduction becomes more important than improving efficiency as soon as a reasonably high COPs are 
reached. This effect is stronger the higher $\Delta a_{\text {spec }}$ of the system is.

Earnings from an investment in heat pump or active condensing technology can be calculated using $\Delta a_{\text {spec }}$ if the cost of gas and electricity are known. Figure 10 displays the result of (10), assuming an electricity price of $80 € \mathrm{MWh}^{-1}$ and a combined gas price of $40 € \mathrm{MWh}_{\mathrm{HHV}^{-1}}$. This representation can be used to decide between different systems or improve research and development efforts. If e.g. a costumer has an offer for two products with different costs and COPs, e.g. a COP of 4 and a $\Delta a_{\text {spec }}$ of $30 € \mathrm{MW}^{-1} \mathrm{~h}^{-1}$ for system A and a COP of 3 and a $\Delta a_{\text {spec }}$ of $20 € \mathrm{MW}^{-1} \mathrm{~h}^{-1}$ for system B, it is not immediately clear which is preferable. Using Figure 10 it becomes clear that hourly earnings for System A compared to a gas boiler would be $0 € \mathrm{MW}^{-1} \mathrm{~h}^{-1}$ whereas system B would earn $3.33 € \mathrm{MW}^{-1} \mathrm{~h}^{-1}$, equaling $10000 € \mathrm{a}^{-1}$ in the case of 3000 full load hours per year.

This representation allows customers to choose the heat pump system with the greatest financial benefit more easily than common approaches and facilitates allocating an economic value to higher COPs or lower investment cost.

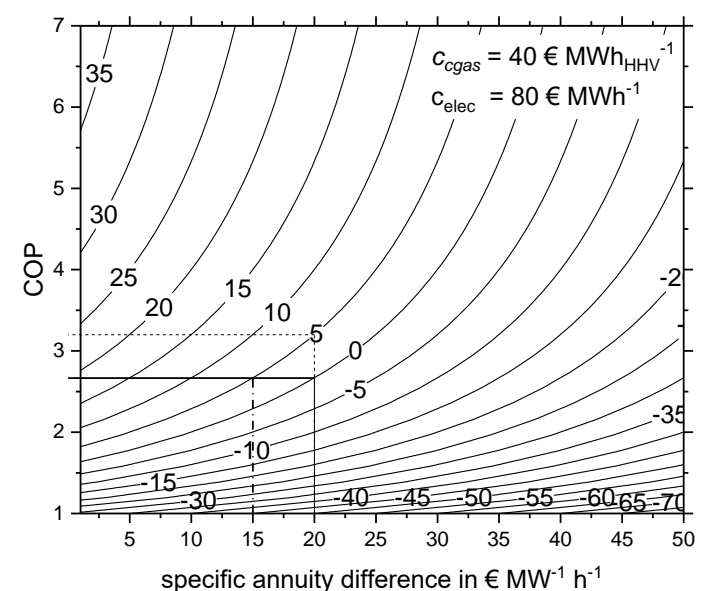

Figure 10. Earnings per full load hour in $€ M W^{-1} h^{-1}$ due to the installation of a heat pump system in comparison to a gas boiler at a boiler efficiency (HHV) of 0.8 .

For research institutes and companies, it may be relevant to decide if research funds should be invested in a reduction of product cost or an improvement of COP. In Figure 10, the straight horizontal and vertical lines mark different example cases. The performance of the current system is marked with solid lines. It is assumed that in a hypothetical consumer specific use case the specific annuity difference is $20 € \mathrm{MW}^{-1} \mathrm{~h}^{-1}$ and the COP is 2.67. If the desired additional value for the costumer is $5 € \mathrm{MW}^{-1} \mathrm{~h}^{-1}$ this can be realised by lowering the specific annuity difference to $15 € \mathrm{MW}^{-1} \mathrm{~h}^{-1}$ (dot-dash line), by improving the COP to 3.2 (dotted line) or a combination of both that lies on the $5 € \mathrm{MW}^{-1} \mathrm{~h}^{-1}$ contour. After evaluation which goal, a $25 \%$ cost reduction, a COP increase by 0.53 points or a partial achievement of both, can be achieved with less funds an investment decision can be made.

Either application, choosing the economic system or helping investment decisions, can also be achieved using traditional methods such as return on invest or net present value. The main advantage of the specific annuity approach lies in the easy communication because of the graphic representation of various configurations in one figure.

\section{Conclusions}

The potential for heat recovery from flue gas in natural gas systems with high air to fuel ratio such as gas turbines and low air to fuel ratio such as flame tube boilers was compared, depending on return temperature, COP and temperature difference of the active condenser system. In addition an analysis of the cost functions with the introduction of the specific annuity difference was performed. To this end a combined gas price, taking into account the gas price as well as carbon emission cost was calculated, at which cost parity with a boiler system is given. Additionally figures allowing for easy comparison of different systems and research decisions regarding cost and COP have been derived, resulting in the following conclusions:

1. Active condensation technology as preheating is influenced little by flow temperatures if return temperature change is small.

2. The influence of the COP on the recovery of flue gas potential can be significant if only little flue gas condensation takes place.

3. The higher flue gas mass flow in the case of gas turbines overcompensates the higher condensation achievable in boilers for a wide area of temperature differences and return temperatures.

4. Economic viability does not directly depend on flue gas potential and temperature level.

5. The specific annuity difference is suitable to compare different technologies based on their cost and COP.

6. The COPs influence on the economic viability is inverse to its value and is greater at higher $c_{\text {elec }}$.

7. As the specific annuity difference's influence on economic viability is independent of COP and electricity price, it becomes more important at low electricity prices and a higher COP.

8. At relatively low COPs, the specific annuity difference of gas powered heat pump systems becomes dominant over further COP improvement regarding economic viability.

9. The specific annuity difference is especially advantageous because the economic performance of different possible choices, especially regarding research and development, can be communicated easily due to the comparison of various possible choices in one figure.

\section{Acknowledgement}

The authors acknowledge the financial support by the Federal Ministry for Economic Affairs and Energy of Germany in the project CleanTechCampus, FKZ 03ET1407A.

\section{Nomenclature \\ $a \quad$ annuity of an investment, $€$ \\ $c \quad$ cost, $€$ \\ $Q \quad$ heat, $\mathrm{kWh}$ \\ $\dot{Q}$ heat flow, $\mathrm{kW}$ \\ $T \quad$ temperature, ${ }^{\circ} \mathrm{C}, \mathrm{K}$}

\section{Greek symbols}

$\Delta \quad$ difference

$\varepsilon \quad$ emission factor, tons $\mathrm{CO}_{2} \mathrm{MWh}_{\mathrm{HHV}^{-1}}$

$\eta \quad$ efficiency 
air ratio, air mass flow / stoichiometric air mass flow

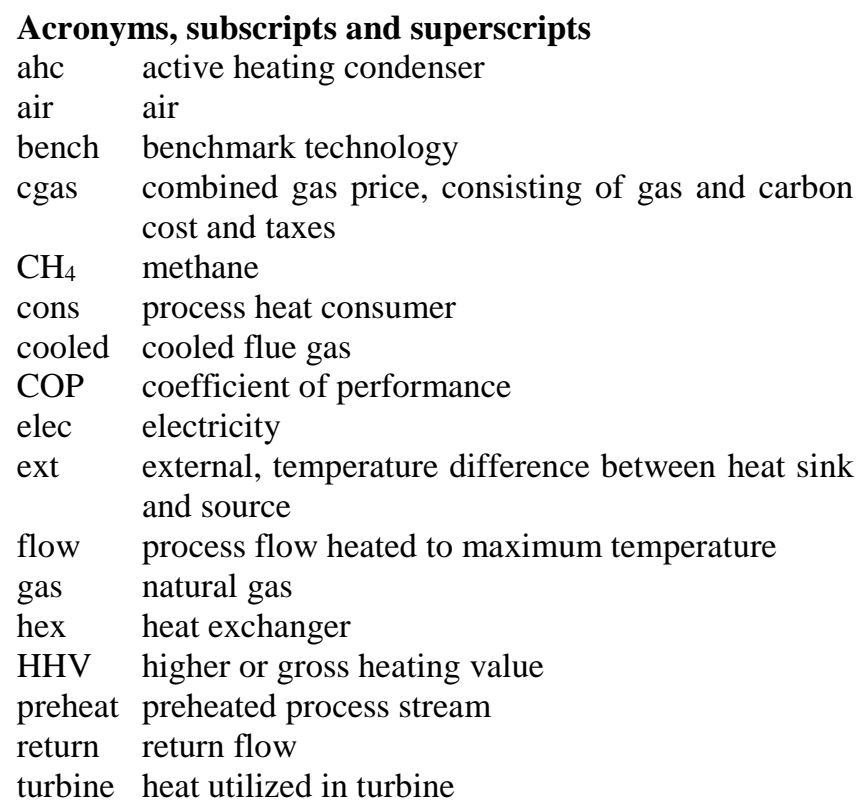

\section{References}

[1] Q. Chen, K. Finney, H. Li, X. Zhang, J. Zhou, V. Sharifi, J. Swithenbank, "Condensing boiler applications in the process industry," Applied Energy, doi: 10.1016/j.apenergy.2010.11.020.

[2] B. Hebenstreit, R. Schnetzinger, R. Ohnmacht, E. Höftberger, J. Lundgren, W. Haslinger, A. Toffolo, "Techno-economic study of a heat pump enhanced flue gas heat recovery for biomass boilers," Biomass \& Bioenergy, doi: 10.1016/j.biombioe.2014.01.048.

[3] M. Wei, X. Zhao, L. Fu, S. Zhang, "Performance study and application of new coal-fired boiler flue gas heat recovery system," Applied Energy, doi: 10.1016/j.apenergy.2016.11.132.
[4] Y. Li, M. Yan, L. Zhang, G. Chen, L. Cui, Z. Song, J. Chang, C. Ma, "Method of flash evaporation and condensation - heat pump for deep cooling of coalfired power plant flue gas: Latent heat and water recovery," Applied Energy, DOI: 10.1016/j.apenergy.2016.03.017.

[5] D. Panepinto, M.C. Zanetti, Municipal solid waste incineration plant: "A multi-step approach to the evaluation of an energy-recovery configuration," Waste Management, doi: 10.1016/j.wasman.2017.07.036.

[6] VDI-GBG, VDI Richtlinie 6025 - Economy calculation systems for capital goods and plants. Düsseldorf, Germany, VDI-Verlag, 2012.

[7] BMWi, Strompreise für Industriekunden in ausgewählten europäischen Ländern nach Verbrauchsmenge im Jahr 2016 (in Euro-Cent pro Kilowattstunde). [Online]. Available: https://de.statista.com/statistik/daten/studie/151260/u mfrage/strompreise-fuer-industriekunden-in-europa/ (accessed Feb. 08, 2018).

[8] A. Kossoy, G. Peszko, K. Oppermann, N. Prytz, N. Klein, K. Blok, L. Lam, L. Wong, B. Borkent, State and Trends of Carbon Pricing. Washington DC, USA, World Bank Group, 2015 Sep. Report No.: 99533.

[9] D. Hirst, Carbon Price Floor (CPF) and the price support mechanism. London, UK, House of Commons Library, 2018 Jan. Briefing Paper No.: 05927.

[10] Macrotrends. Natural Gas Prices - Historical Chart. [Online]. Available: http://www.macrotrends.net/2478/ natural-gas-prices-historical-

chart'>Natural Gas Prices - Historical Chart (accessed Feb. 09, 2018).

[11] Generalzolldirektion, Steuersätze für Energieerzeugnisse nach $\S 2$ Abs. 1 EnergieStG. [Online]. Available: http://www.zoll.de/DE/Fachthemen/Steuern/Verbrauc hsteuern/Energie/Grundsaetze-Besteuerung/Steuerhoe he/steuerhoehe_node.html (accessed Feb. 09, 2018). 